\title{
TANTANGAN PENGEMBANGAN EKOWISATA BAHARI DI PULAU PISANG PESISIR BARAT LAMPUNG
}

\author{
Etik Ipda Riyani \\ Tamjuddin \\ Fakultas Ekonomi Universitas Terbuka \\ etik@ut.ac.id dantamjuddin@ut.ac.id
}

\begin{abstract}
ABSTRAK
Etik Ipda Riyani dan Tamjuddin: Penelitian ini bertujuan mengetahui pengembangan Ekowisata Bahari di sekitar zona wisata Pulau Pisang sebagai salah satu tempat wisata yang diandalkan di kecamatan Pesisir Barat Lampung. Melihat kondisi dan potensi pulau ini berpeluang sebagai destinasi wisata bahari, dan tantangan dalam upaya mewujudkan sebagai wahana pelestarian alam yang akan mendatangkan pendapatan bagi masyarakat, pemda dan pengelola wisata di kawasan pesisir barat, tidak sedikit hambatan dalam mengelola asset wisata ini karena membutuhkan pembangunan infrastruktur. Lokasi penelitian sepanjang pesisir pantai dan zona wisata bahari di kecamatan pulau pisang, Dalam penelitian ini sebagian tindak lanjut kesesuaian zona penelitian sebelumnya, kawasan pantai, snorkeling, diving bagian utara pulau pisang oleh Nugraha, Irfan dkk. (2013). Pentingnya penelitian ini dilakukan, untuk mengetahui tantangan dan masalah dalam pengembangan sektor pariwisata sebagai pengambilan kebijakan terutama pemerintah daerah dan pengelola. Metode penelitian, data dikumpulkan melalui survei ke lapangan, observasi dan wawancara kepada responden. Sampel responden adalah masyarakat pulau, wisatawan, pelaku usaha, aparatur pemerintah tingkat kepala desa, kecamatan, dinas pariwisata dan pemangku kepentingan. Analisis data dalam penelitian ini menggunakan SWOT analisis. Strategi pengembangan didasarkan pada aturan, zona ekowisata bahari, kajian penelitian sebelumnya, pengalaman masyarakat pulau, kebutuhan infrastruktur, SDM dan budaya adat istiadat. Hasil dari penelitian ini keterlibatan penduduk, zonasi ekowisata pantai dan bawah laut, di sekitar pantai pulau pisang.
\end{abstract}

\section{ABSTRACT}

Etik Ipda Riyani dan Tamjuddin: The purpose of this research is to identify the marine ecotourism development of the Pisang Island that is one of the favourite destination in west coast of Lampung. According to condition and the potencies of this island which likely has a potentiality as a further ecotourism destination and also nature conservation that will bring a revenue for the local communities, local governmemt and also management in west coast of Lampung. There are many problems for managing tourism assets because it requires infrastructure development. The research is located along the coast and marine ecotourism zone of Pisang island. This research is the development as further research of previous research which is about the beach, snorkling and diving zone in north coast of Pisang island by Nugraha and Irfan (2013). The importance of this research is to know the challenges and problems in decision making of tourism-developing sector for local goverment and managemet. The methods of this research are direct survey, observation to collect the data and also interview with respondents. The local communities, tourists, the local entrepreneurs, the local governments such as subdistrict head, district head and head of locat department tourism are the sample of respondents. Data analysis is used by SWOT for formulation. The strategy of development are based on the policies, the marine ecotourism zone, the previous reseach analysis, the experience of local communities, infrastructure demands, human resources and the local culture The involvement of local cummunities, the beach marine ecotourism zone and underwater zone are the result of the research.

Key words: Pisang Island, The Challenges Of Policy, Zone, Infrastructure, Human Resources 


\section{PENDAHULUAN}

Pulau Pisang mempunyai karakteristik yang sangat alami, lautnya yang terdapat banyak lumbalumba menjadi kelebihannya. Pulau yang ada di Lampung ini pun semakin alami karena belum adanya listrik dan penginapan. Pulau Pisang adalah salah satu pulau paling barat yang ada di Propinsi Lampung yang langsung menghadap Samudra Hindia. Pulau ini merupakan satu kecamatan sendiri dalam Kabupaten Pesisir Barat, Propinsi Lampung. Asal mula nama Pulau Pisang yaitu dari bentuknya seperti pisang. jika dilihat dari puncak daratan Pulau Sumatra pulau ini terlihat berbentuk pisang, sehingga nama ini sangat populer di daerah tersebut. Untuk menempuh pulau ini kita harus menjelajah daerah barat Propinsi Lampung, diawali dengan perjalanan darat menuju Kota Krui dengan jarak tempuh kurang lebih 7 jam menggunakan kendaraan dari Kota Bandar Lampung.

Perjalanan menuju pulau ini dapat melalui dua akses yaitu pertama melalui daerah Tembakak. Dari Tembakak ini hanya memerlukan waktu sekitar setengah jam menggunakan perahu untuk mencapai pulau ini, sedangkan akses kedua melalui dermaga Krui, dari dermaga ini menggunakan perahu yang membutuhkan waktu sekitar satu jam dengan menyewa kapal nelayan yang bermuatan maksimal 20 orang.

Perkampungan di Pulau Pisang dapat dinikmati dengan adanya kasana budaya lokal yang meliputi bentuk rumah khas adat Lampung, masyarakat yang ramah, ikan segar, dan pembuatan tapis. Tapis merupakan pakaian adat Lampung dan terkenal paling bagus kualitas nomor satu adalah buatan dari pengrajin masyarakat Pulau Pisang. Selain itu, di pulau ini para wisatawan dapat menikmati agrowisata perkebunan cengkeh yang tumbuh subur. Di Lampung, Pulau Pisang terkenal sebagai penghasil cengkeh dari zaman penjajahan dulu. Pulau Pisang juga terkenal sebagian warganya sebagai nelayan dan merupakan salah satu pemasok ikan di wilayah Lampung Barat. Pulau Pisang memberikan sensasi tersendiri.

Pulau Pisang merupakan pulau wilayah Kabupaten Pesisir Barat, Provinsi Lampung. Pulau Pisang memiliki luas daratan 148,82Ha. Secara Geografis pulau pisang terletak pada koordinat 5' \&' 15.000 " LS dan 103' 50' 45.138" BT. Bagian barat dan selatan pulau tersebut berbatasan langsung sengan Samudera Hindia, sedangkan bagian Utara dan Timur berbatasan dengan Pulau Sumatera. Pulau Pisang yang merupakan wilayah satu kecamatan memiliki 6 (enam) desa, yaitu Pekon Labuhan, Pekon Pasar, Sukadana, Suka Marga, Pekon Lok, dan Bandar Dalam. Secara administrasi Pulau Pisang terletak pada kecamatan Pulau Pisang, Kabupaten Pesisir Barat, Provinsi Lampung. Status tanah yang berada di Pulau Pisang sebagian bersertifikat dan sisanya berstatus kepemilikan ulayat/adat.

Sumberdaya alam Pulau Pisang merupakan salah satu andalan sektor wisata pantai maupun potensi laut sesuai dengan hasil penelitian lokasi wisata terletak pada bagian utara pulau untuk wisata bawah laut yang belum tergarap, potensi bawah laut ini dapat dikembangkan untuk wisata perairan pada kedalaman tertentu seperti snorkeling dan diving, karena kedalaman bukan termasuk laut dalam dan terdapat kecerahan air serta sejumlah jenis ikan karang menghiasi kedalam area wisata bawah laut, sedangkan untuk sepanjang pesisir dapat digunakan untuk wisata pantai, mandi berenang, menyusuri pantai, keliling pulau berjalan atau berperahu, sementara ada penduduk yang melakukan kegiatan bawah laut bukan untuk wisata tetapi mencari ikan tangkapan jenis ikan karang dengan cara menyelam dan menggunakan panah ikan, tombak, sisi lain dasar pemikiran pengembangan ekowisata bahari untuk terkait wisata alam, yang berbasis keterlibatan masyarakat lokal dimana pengunjung dapat mempertahankan kelestarian alam, budaya lokal dan proses edukasi. Penelitian Nugraha 2011 yang diterbitkan Journal Marine UNDIP 2013 vol 2 no.3. Pulau Pisang bagian utara kedepan merupakan salah satu zona andalan Daerah Tujuan Wisata psesisir barat propinsi Lampung, dapat dilihat hasil dari penelitian tersebut ada kesesuaian dengan lokasi perairan untuk wisata bahari, dengan indeks kesesuaian (IKW) dimana lokasi pada terdapat 13 stasiun dari 15 stasiun termasuk kategori sangat sesuai (S1) dan Charisma dkk, 2013 Pulau Pisang berpotensi untuk wisata pantai nilai S1, dengan beberapa kegiatan susur pantai, berjemur, memancing. Untuk susur pantai menjelaskan sangat sesuai (S1) dengan Indeks Kesesuaian Wisata 93\% untuk berjemur IKW 94\% dengan katagori nilai S2 dan untuk kegiatan memancing cukup sesuai nilai IKW sebesar $70 \%$, sesuai den zona pemancingan. 
Tantangan pembangunan dan industrialisasi wilayah pesisir dan lautan membawa dampak terhadap penduduk, dukungan sumberdaya dan masalah utamanya adalah penduduk yang dihadapkan dengan perkembangan lingkungan industry, kondisi masyarakat pulau mengambil keputusan tepat untuk melihat masalah sebagai peluang dalam meningkatkan penghasilan dan kesejahteraan, pencaharian, saat ini terjadi pergeseran kegiatan ekonomi, baik sebagai nelayan tangkap dengan teknologi sederhana belum ada penggunaan alat tangkap yang ramah lingkungan +) atau masyarakat berkegiatan menjadi petani cengkeh dan kelapa, kakao atau mengumpulkan hasil laut sebagai pewaris dan jasa penyeberangan untuk mengantar warga atau tamu-tamu pengunjung wisata ke pulau pisang andalan pada kemurahan alam, Kegiatan jasa transportasi angkutan laut ke wilayah daratan di pesisir barat Lampung. Pengembangan potensi ekowisata bahari butuh penggerak untuk menumbuhkan berbagai kegiatan ekowisata, merupakan kebutuhan utama, butuh sarana pendukung untuk kegiatan ekonomi dan sosial, mendorong pertumbuhan ekonomi lokal terbatas. Hasil wawancara dengan masyarakat bahwa pasokan listrik terbatas dan infrastruktur termasuk sarana umum penyeberangan ke pulau, fasilitas dan kebutuhan yang sangat diharapkan oleh masyarakat, kurangnya penyediaan sarana telah menjadi penyebab perlambatan pertumbuhan ekonomi lokal, daya beli masyarakat rendah karena penghasilan dari matapencaharian tergantung musim karena sumber dan pasar tidak pernah mencapai skala normal.

Basis penduduk pesisir yang mendiami atau betempat tinggal di pulau pisang terlihat pada Gambar 1 dibawah ini. Dari sejumlah anggota keluarga dan status KK 346 dari 497 sekitar hampir 0,70 penduduk bertempat tinggal dipesisir pantai dan sebagian besar pekerjaan mengandalkan pencaharian dari hasil nelayan, penduduk lainnya tinggal di desa atau pekon yang dekat dengan kebun cengkeh, kelapa dan kakao.

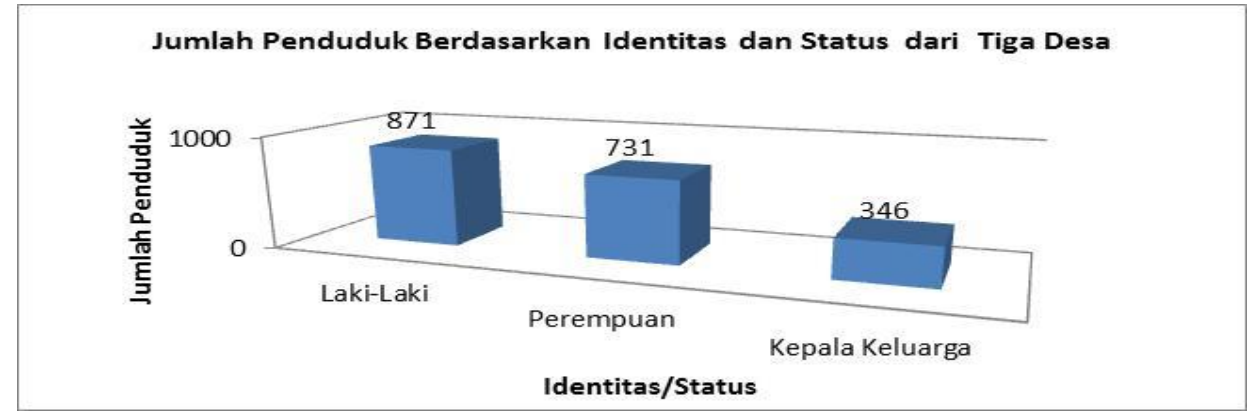

Gambar 1. Jumlah Penduduk berdasarkan Identitas dan Status dari Tiga Desa

Sumber diolah: Direktori DKP 2013

Berdasarkan hasil survey sumber informasi aparat pemerintahan setempat penduduk hasil observasi, dokumen pulau-pulau kecil dan penduduk yang berdiam di pekon pesisir pantai lebih dominan dalam mengembangkan aktifitas di bidang perikanan dan kelautan (2012).

Penelitian ini bertujuan untuk mengembangkan dan meningkatkan ekowisata bahari yang memiliki sumber daya sosial dan ekonomi berwawasan lingkungan dan pembangunan berkelanjutan dalam mengelola wisata bahari secara tepat dan profesional, peran masyarakat lokal meningkat dalam mencapai kesejahteraan masyarakat, untuk mengembangkan konservasi dan kelestarian, dapat mengundang pihak yang kompeten dan berminat untuk mengembangkan wisata bahari.

\section{METODE PENELITIAN}

Penelitian ini dilaksanakan pada bulan Juni sampai Desember di Kabupaten Pesisir Barat Lampung. Teknik pengumpulan data pada penelitian ini menggunakan observasi dan wawancara yang dilaukan pada bulan Oktober dan Desember 2015. Metode penelitian yang digunakan melaui survey dan mengumpulkan data berupa data demografi kualitatif dan kuantatif penduduk Pulau Pisang, aktivitas masyarakat disekitar pulau, data desa dan kecamatan, kegiatan dan objek wisata, nelayan, pelaku usaha, pemangku kebijakan peratin desa/pekon, dan camat dinas pariwisata. Dari informasi pengunjung 
ekowisata meliputi ketertarikan wisatawan terhadap pantai yang alami, gugusan karang, menyusuri pantai dan lingkungan pulau memancing, berperahu keliling pulau, menyelam dan snorkeling. Sarana pendukung akomodasi, penginapan rumah peduduk, homestay, tempat makan, pemandu wisata.

Metode analisis mengunakan Analisis SWOT untuk evaluasi kinerja faktor internal dan eksternal sebagai bahan pertimbangan untuk berinvestasi, metode ini merupakan perencanaan strategis mengevaluasi kekuatan, kelemahan, peluang dan ancaman (Strenght, Weaknesses, Opportunities, and Threats). Metode analisis ini dianggap banyak digunakan karena alat ini dianggap tepat untuk menentukan masalah dari empat sisi yang berbeda, dari aplikasi bagaimana mampu mengambil manfaat atau meraih keuntungan dari potensi yang ada dan bagaimana cara mengatasi kelemahan yang membuat ancaman nyata atau ada ancaman baru yang diciptakan.

Datap rimer dan sekunder juga digunakan dalam penelitian ini. Data primer diperoleh dengan pengamatan observasi langsung, dokumentasi di lokasi Pulau Pisang, dan observasi di pelabuhan penyebrangan Jukung. Wawancara dilakukan dengan responden yang terdiri dari warga masyarakat pulau pisang yang memiliki status sebagai nelayan, pengelola homestay, aparat desa peratin, petani, pemandu wisata, pedagang kelontong, warung makanan, dinas pariwisata dan ekonomi kreatif, pengelola bungalows, dan wisma. Data sekunder diperoleh dari literatur dan jurnal yang berhubungan dengan penelitian ini.

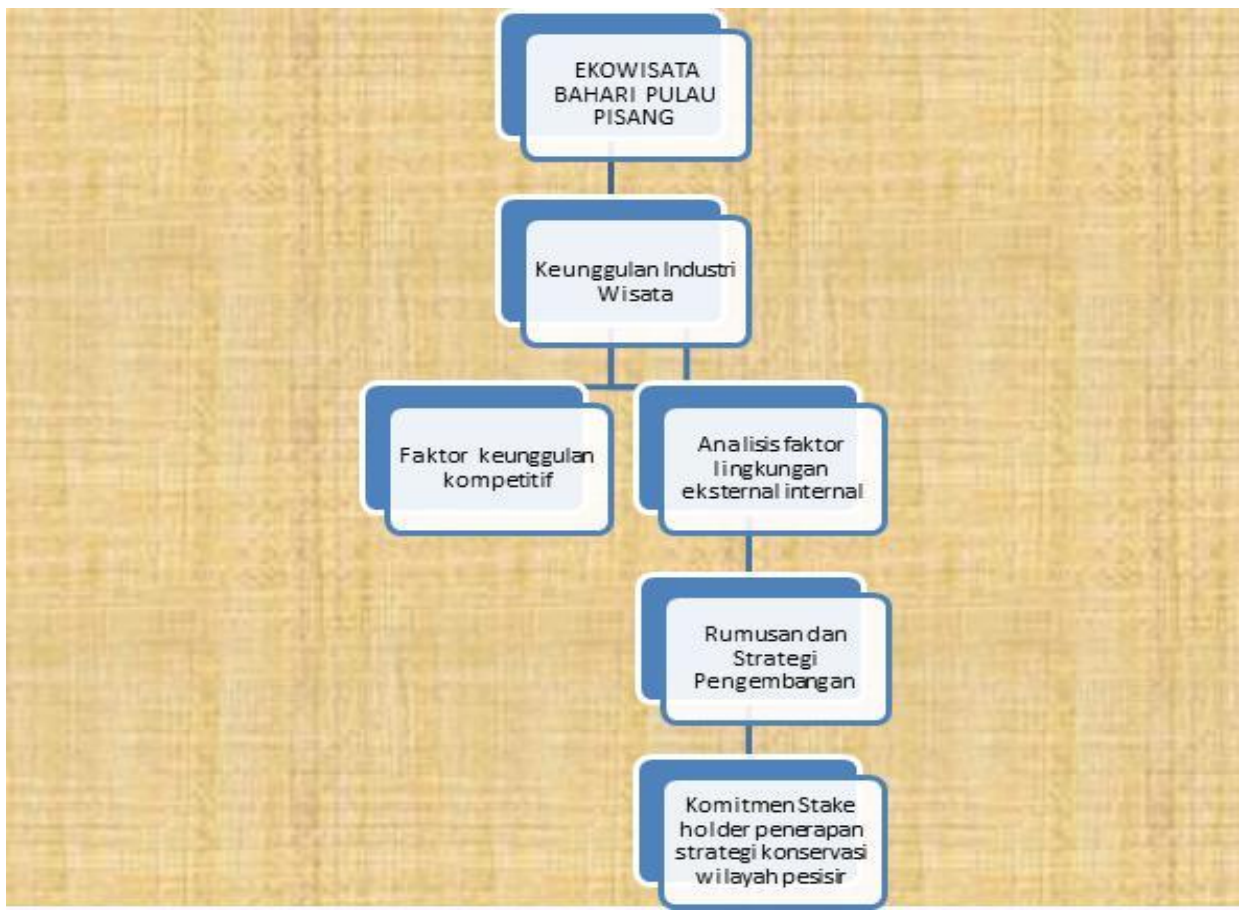

Gambar 2. Kerangka Pemikiran Penelitian Wisata Bahari

\section{HASIL DAN PEMBAHASAN}

Gambaran umum penduduk Pulau Pisang dikelompokkan dalam dua kelompok masyarakat berdasarkan tempat tinggal yang berkaitan dengan aktivitas secara umum sebagai petani, nelayan dan pelaku jasa, mereka bertempat tinggal di pekon, posisinya berada di dataran atas terdiri dari tiga pekon atau desa, yakni desa LOK Bandar dalam, Sukamarga yang berdomisili lokasi bukit terdapat 151 Kepala Keluarga yang memilki kebun sebagai petani pada umumnya mereka tidak bekerja sebagai nelayan, dari sejumlah penduduk disini, hasil wawancara dengan responden terdapat 180 orang yang tidak sanggup untuk melaut karena bukan profesi nelayan atau karena takut. 
Beberapa aspek kunci ekowisata bahari yang basisnya masyarakat:

1. Masyarakat membentuk panitia atau kelompok pengelola kegiatan ekowisata bahari di dukung oleh pemerintah dan organisasi masyarakat, mengimplementasikan nilai dan partisipasi masyarakat melakukan edukasi ekowisata

2. Pengelolaan dan melibatkan kepemilikan masyarakat setempat tehadap sarana dan parasarana pada kawasan ekowisata

3. Sarana akomodasi di lokasi wisata berupa homestay memiliki nilai ekonomi dan edukasi, komunikasi sosial dapat terbangun, iklim memanfaatkan sarana untuk kepentingan masyarakat disarkan atas norma.

4. Pemandu wisata merupakan bagian dari partisipasi masyarakat dapat dilakukan oleh penduduk local.

5. Perintisan ekowisata pengelolaan dan pemeliharaan obyek wisata menjadi tanggung jawab masyarakat setempat termasuk penentuan biaya untuk wisatawan nilai ekonomi dan wisata pemungutan tarif (fee)

\section{Daya Dukung dan Strategi Ekowisata Bahari}

1. Konsep ekowisata memperhitungkan pemanfaaatan ruang dan kualitas daya dukung dari kegiatan di lingkungan kawasan tujuan wisata, pengaturan melalui sistem zonasi dengan cara mengatur kunjungan wisatawan, menentukan jumlah dan waktu yang masuk kepulau pisang

2. Kegiatan wisata mendukung program penghijauan, mencegah reboisasi, serta penggunaan sarana penangkapan ikan yang dapat merusak lingkungan, penggunaan bahan bakar kayu untuk rumah tangga secara berlebihan,

3. Rancangan fasilitas umum sesuai dengan kebiasaan tradisi masyarakat lokal yang terlibat dalam perencanaan pembangunan zonasi wisata dan kemudahan prasana transportasi darat, laut dan udara,

4. Fasilitas pendukung yang tidak merusak ekosistem keunika dan kerentanan, berkerjasama dengan kelembagaan untuk riset konservasi keragaman bawah laut,

5. Kegiatan keseharian mencari ikan, melakukan panen atau berburu dapat dimasukkan kedalam agenda atraksi lokal, memperkenalkan ke wisatawan bagaiman cara hidup masyarakat dan mengajak mereka agar dapat menghargai pengetahuan dan kearifan budaya lokal

6. Belum, Mengembangkan paket wisata yang mengedepankan budaya seni, nilai budaya yang sudah menjadi tradisi masyarakat,

7. Menyediakan tempat disekitar fasilitas umum dan sampah rumah tangga. dan sistem pengolahan sampah belum efektif

Dalam pengembangan pemasaran dan strategi branding untuk produk ekowisata sangat penting, tindakan yang dapat dilakukan dengan membuat strategi melalui:

1. Kegiatan pomosi dan pemasaran dengan skala tertentu

2. Melakukan Survei pasar, melakukan segmented secara berkala untuk dapat mengetahui dinamika pasar yang berkembang.

3. Mengidentifikasi target pasar untuk ekowisata yang hendak dikembangkan

4. Menyelenggarakan promosi khusus, paket wisata dengan memanfaatkan media dll.

5. Menjalin hubungan dengan pihak swasta, agent tourism atau membuat kesepakatan organisasi masyarakat dengan pengelola wisata.

Zona dan pengaturan adalah salah satu pendekatan yang akan membantu dan menjaga nilai konservasi berkelanjutan kawasan ekowisata; kriteria ini memperhatikan: 
1. Kegiatan ekowisata telah memperhitungkan tingkat pemanfaatan ruangan dan kualitas daya dukung lingkungan dan kawasan melalui pelaksanaan system zonasi bertujuan untuk pengaturan kunjungan wisatawan.

2. Faslitas pendukung yang dibangun tidak membuat kerusakan atau pada ekosistem yang unik dan rentan pada kerusakan alami

3. Rancangan fasilitas umum disesuaikan dengan tradisi lokal dan masyarakat terlibat dalam proses perencanaan dan pembangunan kawasan ekowisata bahari

4. Terdapat sistem pengelolaan sampah disekitar fasilitas umum dan sejauh mana sampah dilakukan daur ulang

5. Kegiatan ekowisata mendukung program reboisasi, penghijauan tanaman dan pohon yang tahan terhadap cuaca dapat menyimpan cadangan air tanah.

Rencana pengembangan kawasan bahari harus dikaitkan dengan berbagai kepentingan yang mendasar, yaitu pemberdayaan masyarakat pesisir. Masyarakat pesisir adalah masyarakat yang memiliki banyak pengetahuan tentang kondisi obyektif wilayahnya, oleh Karena itu dalam pengembangan kawasan wisata bahari, senantiasa hendaknya di mulai pendekatan terhadap masyarakat setempat sebagai suatu model pendekatan perencanaan partisipatif yang menempatkan masyarakat pesisir memungkinkan saling berbagi, meningkatkan dan menganalisa pengetahuan mereka tentang bahari dan kehidupan pesisir, membuat rencana dan bertindak. Pembangunan yang berpusat pada masyarakat lebih menekankan pada pemberdayaan (empowerment), yang memandang potensi masyarakat sebagai sumber daya utama dalam pembangunan dan memandang kebersamaan sebagai tujuan yang akan dicapai dalam proses pembangunan. Masyarakat pesisir adalah termasuk masyarakat hukum adat yang hidup secara tradisional di dalam kawasan pesisir maupun di luar kawasan pesisir. Oleh karena itu dalam rangkapengelolaan kawasan wisata bahari maka prinsip dasar yang harus dikembangkan adalah:

1. Prinsip kawasan wisata bahari adalah milik bersama ada hak masyarakat yang harus diakui termasuk perlindungan bersama. Batas sempadan pantai, kebersihan, menjaga kenyamanan, keamanan lokasi wisata.

2. Prinsip manajemen yaitu bahwa kepemilikan bersama mengharuskan, pengelolaan pesisiruntuk dilakukan bersama-sama seluruh komponen masyarakat (stakeholder) yang terdiri dari pemerintah, masyarakat dan organisasi non pemerintah yang harus bekerja sama

3. Prinsip keberadaan kawasan wisata bahari menjadi tanggung jawab bersama karena pengelolaan kawasan wisata bahari merupakan tujuan Bersama Ketiga prinsip tersebut dilaksanakan secara terpadu, sehingga fungsi kelestarian pesisir tercapai dengan melibatkan secara akitif peran serta masyarakat sekitar pesisir.

Masyarakat mampu berpartisipasi, perlu keberdayaan baik ekonomi, sosial dan pendidikan, untuk itu dibutuhkan peran pemerintah dalam memberdayakan masyarakat sekitar pesisir agar meningkatkan melalui 6 prinsip pemberdayaan, agar masyarakat berdaya yaitu:

1. Membangun. visi misi dan rencana strategis bidang wisata yang ramah lingkungan

2. melakukan kerjasama dan berdasarkan-nilai kesepakatan sebagai modal sosial

3. Infrastruktur dan pengembangan masyarakat yang berorientasi untuk kemajuan

4. Orientasi model pengembangan wisata pengembangan yang bertumpu kemampuan dan kepemilikan masyarakat

5. Kerjasama (collaboration) yaitu mengembangkan pola kerjasama yang tumbuh dari dalam

6. Menumbuhkan partisipatif peran masyarakat untuk berkembang lebih mandiri 
Table 1. Matrik Analisis SWOT

1. Daya tarik dan potensi alam, wisata pantai, bawah laut snorkeling, diving, lokasi mancing/selancar.

2. Budaya dan adat masyarakat lokal menarik untuk kunjungan wisata

3. Suasana masyarakat religi sebagai kekuatan pranata sosial

4. Sarana pengelolaan air bersih cukup tersedia

5. Kantor kecamatan mendukung kordinasi dengan pemerintahan kabupaten

6. Penciptaan lingkungan aman

7. Jalan lingkungan paving blok, semen

8. Tersedia lahan tempat berkumpul jumlah banyak orang

9. Peningkatan kelola homestay/ rumah penduduk

10. Suasana pantai secara umum bersih

11. Kerjasama kementrian, lembaga dan media
1. Transportasi, sarana angkutan

2. Belum ada standar tariff retribusi ke pulau

3. Fasilitas pasokan listrik PLN belum ada, masih andalkan genset

4. Dermaga pelabuhan belum berfungsi, kapasitas kecil dan berbahaya bagi penumpang

5. Layanan komunikasi terbatas, hanya satu provider/hanya ada satu BTS

6. Ketergantungan musim ombak untuk surfing

7. Komunikasi, akomodasi dan promosi

8. Sertifikat bahasa asing bagi pemandu

9. Kualifikasi SDM rendah untuk medukung ekowisata bahari

10. Kegiatan kelompok sadar wisata belum berperan

11. Rumah penduduk, homestay yang belum terawat

12. Segmen kebutuhan pasar kecil

13. Sistem pengelolaan sampah umum belum berfungsi

\section{PELUANG}

ANCAMAN

\section{(Opportunities)}

1. Akses dekat dengan kota kabupaten

2. Pengembangan daerah otonomi baru

3. Pengrajin dilatih disain lokal

4. Pelatihan nelayan terampil/budi daya

5. Potensi SDA hayati non hayati besar

6. Memiliki heritage, sejarah, produk seni kriya lokal menarik

7. Sarana pendukung bandar udara serai mempercepat jalur ke pulau

8. Dekat Kawasan TNBBS (Taman Nasional Bukit Barisan) hutan konservasi (paket wisata)

9. Lahan Riset Flora-Fauna

10. Memanfaatkan paket wisata andalan/tour joint promotion

11. Kerjasama International Resort and leisure pockets

\section{(Threats)}

1. Ancaman Samudra Hindia

2. Dampak kawasan longsor, banjir

3. Jalur gempa tektonik, tsunami

4. Tata kelola image wisata buruk

5. Pencemaran dampak lingkungan

6. Kawasan konservasi yang gagal

7. Disharmonis pelaku kelompok usaha

8. Peraturan zona dan resort wisata tidak memperhatikan kearifan lokal.

9. Pengaruh global warming dari negara asing, kasus ekskusi hukuman mati warga negara asal Australia

10. Saingan dari pengelola wisata lainnya, kawasan wisata pantai pesisir selatan

Dari tabel tersebut diatas dapat dilakukan upaya untuk meminimalkan faktor internal dan eksternal dari berbagai aspek, dimana dilakukan identifikasi aspek kelemahan dan ancaman upaya dalam rangka memformulasikan strategi pada kegiatan Ekowisata Bahari di Pulau Pisang, langkah selanjutnya adalah merumuskan strategi dengan menganalisis faktor internal dan eksternal sehingga dapat berubah jadi Kekuatan dan Ancaman berubah menjadi Peluang untuk sektor usaha wisata bahari Pulau Pisang. Dalam merumuskan strategi pengembangan ekowisata bahari pulau pisang berdasarkan table matriks SWOT menunjukan tentang peluang dan ancaman dari faktor eksternal yang dihadapi mengembangkan ekonomi wisata terdapat konflik kepentingan sebagian masyarakat menghendaki pembangunan wisata yang dapat memberikan nilai tambah secara ekonomi namun dilain pihak terjadi penolakan terhadap pengembangan ekowisata bahari alas an penetrasi budaya asing yang dapat mengerus nilai dan tatanan norma adat setempat, dalam pengembangan ekowisata ini yang perlu ditegaskan menjaga kesesuaian dan harmonisasi tata nilai yang berkembang di masyarakat pulau pisang, seberapa kuat daya tangkal dan ketangguhan untuk menanggulangi kelemahan yang ada dilingkungan adat masyarakat pulau khususnya pulau pisang. Rumusan strategi sebagai berikut:

1. Merumuskan aturan yang disepakati untuk dijalankan oleh pelaku usaha

2. Menyediakan SDM terlatih berwawasan lingkungan pengelolaan ekowisata bahari

3. Menjaga lokasi aman, bersih,nyaman dan tersedia sarpras ke lokasi wisata Penyediaan sarana ke pulau transportasi 
4. Menegakan peraturan yang tertib dalam pelaksanaan berdasarkan hukum secara umum

5. Melakukan Kerjasama dengan lembaga riset konservasi, riset (LIPI) kelembagaan dan bisnis

6. Mengajukan Rancangan pengembangan pulau untuk ekowisata bahari dalam rangka meningkatkan IPM

Tabel 2. Alternatif Strategis Pengembangan Ekowisata Bahari Pulau Pisang

\begin{tabular}{|c|c|c|}
\hline $\begin{array}{l}\text { FAKTOR } \\
\text { EKSTERNAL }\end{array}$ & $\begin{array}{l}\text { KEKUATAN(STRENGHT) } \\
\text { KS 1. Daya tarik potensi bahari, wisata alam } \\
\text { KS 2. Budaya adat masyarakat } \\
\text { KS 3. Kehidupan masyarakat religi } \\
\text { KS 4. Pelatihan, keterampilan, budaya lokal } \\
\text { KS 5. Kondisi lingkungan aman } \\
\text { KS 6. Potensi SDA melimpah } \\
\text { KS 7. Heritage sejarah pulau, seni kriya lokal } \\
\text { KS 8.Bandara udara serai jalur strategis } \\
\text { KS 9.TNBBS (Taman Nasional ) } \\
\text { KS 10.Lahan Riset Flora -Fauna } \\
\text { KS 11.Promosi \& paket wisata andalan } \\
\text { KS 12. Contoh perencanaan DOB mudah } \\
\text { KS 13. JALUR KOMUNIKASI KE KAB DEKAT } \\
\text { KS 13. Potensi SDA Heritage, sejarah pulau, seni } \\
\text { kriya lokal. } \\
\text { KS 14. Prasarana dermaga pelabuhan } \\
\text { pengembangan wisata Pesisir Barat }\end{array}$ & $\begin{array}{l}\text { KELEMAHAN(WEAKNES) } \\
\text { KW 1. Ancaman Samudra Hindia } \\
\text { KW 2. Akses tujuan wisata terhambat dari } \\
\text { Kawasan rawan banjir, longsor } \\
\text { KW 3. Jalur Gempa lempeng tektonik } \\
\text { KW 4.Tata kelola image wisata buruk } \\
\text { KW 5.Pencemaran dampak lingkungan dan } \\
\text { ekosistem } \\
\text { KW } 6 \text { Kawasan Konservasi gagal } \\
\text { KW } 7 \text { Disharmonis kelompok usaha } \\
\text { KW } 8 \text { Aturan zona wisata belum jelas } \\
\text { KW } 9 \text { Kearifan lokal diabaikan. } \\
\text { KW10.Sarana pendukung angkutan laut } \\
\text { kurang baik } \\
\text { KW.11 Sekolah kejuruan sesuai lokal } \\
\text { KW 12. Sarana-Prasarana wisata lemah } \\
\text { KW 13. Pelatihan keterampilan dan budi } \\
\text { daya bagi nelayan yang berhubungan } \\
\text { dengan konservasi }\end{array}$ \\
\hline $\begin{array}{l}\text { PELUANG } \\
\text { (OPPORTUNIT } \\
\text { IES) }\end{array}$ & $\begin{array}{l}\text { STRATEGI S-O } \\
\text { 1. Potensi lokasi pantai, bawah laut, adat } \\
\text { istiadat menarik } \\
\text { 2. Menciptakan suasana penyediaan sarana } \\
\text { akomodasi aman, nyaman, bersih, dan } \\
\text { mengesankan } \\
\text { 3. Daerah pengembangan dekat dengan } \\
\text { kabupaten induk } \\
\text { 4. Perencanaan jalur udara dan sarpras laut } \\
\text { terkait untuk wisata } \\
\text { 5. Potensi riset biota laut, ekosistem } \\
\text { 6. Pengembangan Produk \& budaya } \\
\text { masyarakat pesisir }\end{array}$ & $\begin{array}{l}\text { STRATEGI W-O } \\
\text { 1. Keseriusan pelaku usaha untuk bidang } \\
\text { Ekowisata bahari } \\
\text { 2. Pembangunan Sarana prasarana } \\
\text { diutamakan untuk mengembangkan } \\
\text { potensi ekowisata bahari } \\
\text { 3. Perencanaan pengembangan wisata } \\
\text { daerah otonomi baru lebih mudah } \\
\text { mengikuti rencana pembangunan } \\
\text { kabupaten induk } \\
\text { 4. Pelatihan yang kompenten dan khusus } \\
\text { masyarakat pesisir pulau }\end{array}$ \\
\hline $\begin{array}{l}\text { ANCAMAN } \\
\text { (THREATS) }\end{array}$ & $\begin{array}{l}\text { STRATEGI S-T } \\
\text { 1. Manfaat pembangunan sarana prasarana } \\
\text { bukan untuk kepentingan } \\
\text { 2. Potensi SDA dieksploitasi untuk kepentingan } \\
\text { promosi dan pencitraan. } \\
\text { 3. Jalur Lintas strategis tidak mampu } \\
\text { dimanfaatkan optimal } \\
\text { 4. Ketergantungan wisata asing dalam } \\
\text { meningkatkan nilai tambah, manfaat wisata } \\
\text { mengalir ke masyarakat }\end{array}$ & $\begin{array}{l}\text { STRATEGI W-T } \\
\text { 1. Dukungan komunitas untuk wisata } \\
\text { kurang fokus } \\
\text { 2. Ancaman konservasi gagal } \\
\text { dikembangkan } \\
\text { 3. Persepsi skala prioritas pembangunan } \\
\text { wisata butuh biaya tinggi } \\
\text { 4. Infrastruktur perangkat sosial lemah }\end{array}$ \\
\hline
\end{tabular}




\section{KESIMPULAN}

Strategi pengembangan ekowisata bahari di Pulau Pisang diantaranya daya tarik dan potensi alam, wisata pantai, bawah laut snorkeling, diving, lokasi mancing/selancar, budaya dan adat masyarakat lokal menarik untuk kunjungan wisata, suasana masyarakat religi sebagai kekuatan pranata sosial, sarana pengelolaan air bersih cukup tersedia, kantor kecamatan mendukung kordinasi dengan pemerintahan kabupaten, penciptaan lingkungan aman, jalan lingkungan paving blok, semen, tersedia lahan tempat berkumpul jumlah banyak orang, peningkatan kelola homestay/ rumah penduduk, suasana pantai secara umum bersih, kerjasama kementrian, lembaga dan media.

Namun demikian masih terdapat beberapa kelemahan diantaranya transportasi dan sarana angkutan belum ada standar tariff retribusi ke pulau, fasilitas pasokan listrik pln belum ada, masih mengandalkan genset, dermaga pelabuhan belum berfungsi, kapasitas kecil dan berbahaya bagi penumpang, layanan komunikasi terbatas, hanya satu provider, ketergantungan musim ombak untuk surfing, komunikasi, akomodasi dan promosi belum baik, tidak ada sertifikat bahasa asing bagi pemandu, kualifikasi SDM masih rendah untuk medukung ekowisata bahari, kegiatan kelompok sadar wisata belum berperan, rumah penduduk atau homestay yang belum terawat, segmen kebutuhan pasar masih kecil, dan sistem pengelolaan sampah umum belum berfungsi dengan baik.

Beberapa saran yang dapat diberikan untuk penelitian ini, yaitu bagi pemangku kepentingan dapat membuat peraturan pengelolaan ekowisata bahari, zona, pelaku, sarana, retribusi, diatur secara jelas, menyiapkan SDM yang terampil dan berwawasan melalui berbagai pelatihan, menciptakan lokasi yang aman, bersih, nyaman dan tersedia sarana prasarana ke lokasi wisata, khusus penyediaan sarana transportasi ke pulau, membuat aturan ketertiban dalam praktek hukum secara umum, mendukung peraturan daerah tentang pengelolaan dan kerjasama dengan lembaga riset konservasi.

\section{DAFTAR PUSTAKA}

Agusriyadi dan Aras Mulyadi, Syafrudin Nasution. (2013). Study of Marine Ecotourism Potensial in Balai Island Aceh Singkil Regency of Aceh Province. Fisheries and marine Science faculty of The University of Riau

Bursan, R. (2006). Analisis Pengaruh Dimensi Wisata terhadap loyalitas wisatawan (Studi Kasus di Propinsi Lampung).

http://travel.detik.com/read/2015/01/15/141100/2798271/1025/pulau-pisang-satu-lagi-yang-cantikdi-bandung

Irfan, Lazuardi, Petrus Subardjo, Hariyadi (2013) Analisis kesesuaian perairan untuk wisata Snorkeling dan Diving di pulau pisang bagian utara kecamatan pesisir utara Lampung Barat. Journal of Marine Research Vol 2, nomor 3, Tahun 2013 Halaman 156-165.

Kosana, K.S. (2010). Pengaruh kepuasan terhadap loyalitas dengan pengembangan "Toursat" pada obyek wisata Umbul Sidomukti, Prestasi, Vol. 6 No. 2, 57 - 76.

Putra Charisma Chryssa Sitompul, Petrus Subardjo, Ibnu7 Pratikto (2013). Studi potensi pulau pisang bagian utara untuk perencanaan kawasan wisata pantai, Kabupaten Lampung Barat Propinsi Lampung. Journal of Marine Research Vol 2, nomor 3, Tahun 2013 Halaman 138-146.

Sugiyono (2008). Metode Penelitian Kuantitatif, Kualitatif dan R \& D, Penerbit. Alfabeta, Bandung. 